\title{
Los orígenes de la estrategia mancomunada en el republicanismo español: la democracia por bandera
}

\author{
Sergio Sánchez Collantes \\ Universidad de Oviedo
}

\begin{abstract}
The origins of the community strategy in spanish republicanism: democracy as ideal
\end{abstract}

RESUMEN

Este artículo rescata del olvido los primeros esfuerzos realizados por los republicanos españoles para conseguir

unirse bajo una misma bandera. La primera Unión Republicana de la historia de España parece haberse forjado en Oviedo hacia 1876-1877, pero la reciente ilegalidad del republicanismo impidió el segundo calificativo del binomio, por lo que transitoriamente se empleó el eufemismo Unión Democrática. Los núcleos democráticos ovetenses se esforzaron en difundir su proyecto, por ejemplo dirigiendo una carta a los principales jefes de la democracia en la que argumentaban la necesidad de una coordinación de fuerzas. Aunque la estrategia mancomunada obtuvo un amplio respaldo en la totalidad de las provincias, no tardó en aflorar la discordia, lo que impidió que la Unión Democrática se convirtiera en un proyecto nacional amplio, sólido y efectivo.

PALABRAS CLAVE: republicanismo, democracia, Unión Republicana, Unión Democrática, partidos, Restauración

\section{ABSTRACT}

This article saves from falling into oblivion the first efforts made by Spanish republicans in order to join together under the same flag. The first Unión Republicana in spanish history seems to have been formed in Oviedo towards 1876-1877, but the recent illegal situation of republicanism banned the second adjective of the binomial to be used. For that reason, the euphemism Unión Democrática was the one they used temporary. Democratic centers from Oviedo made several efforts to spread their project, for instance by sending a letter to the main leaders of democratic movement on which they argued the need for a coordination of forces. Although the unitarian strategy obtained a huge support in all provinces, discord didn't take a long time to appear, obstructing the Unión Democrática from becoming a wide, well built and effective national project.

KEYWORDS:

republicanism, democracy, Unión

Republicana (Republican Union), Unión Democrática (Democratic Union), parties, Restoration. 


\section{CONSIDERACIONES PREVIAS ${ }^{1}$}

La presunción de que los orígenes de la acción mancomunada del republicanismo español deben buscarse en los albores de la Restauración constituye el "punto arquimediano» del presente estudio, y se fundamenta en la evidencia de que anteriormente, sin soslayar su heterogeneidad y polémicas internas ${ }^{2}$, sólo existía un partido no monárquico, el Partido Republicano Federal, que se creó en 1868 después de que un sector del Partido Demócrata - los llamados despectivamente cimbrios - se inclinara por la fórmula monárquica ${ }^{3}$. Se trataba, en rigor, de la primera gran reunión de todos los elementos republicanos bajo una misma bandera. En definitiva, era el primer partido con ese signo fundado en España y el único existente durante unos pocos años en los que no cabe buscar una mancomunidad entre partidos republicanos por la sencilla razón de que sólo había uno ${ }^{4}$.

En el periodo de entrerrepúblicas, con mayor o menor fortuna y al margen de que muchas veces sus deseos fueran meramente discursivos, el republicanismo español protagonizó numerosos intentos tendentes a la consecución de una alianza o coordinación de fuerzas entre sus elementos, independientemente de que esta inteligencia antimonárquica fuera total o parcial, de su vigencia, de sus distintas fórmulas o denominaciones —unión, coalición, fusión, conjunción, agrupación...-y de que sus sostenedores fueran partidos, organizaciones o individualidades. El objetivo del presente trabajo es rescatar del olvido histórico e historiográfico el pionero de todos esos intentos, la primera Unión Republicana intentada en la España contemporánea, que aunque no llegó a consumarse más que a nivel local precedió en un cuarto de siglo a la formada en $1903^{5}$, y en unos quince años a su inmediata y efímera antecesora, la de $1893^{6}$. Se trata de la denomi-

1 Agradezco a los profesores Francisco Erice, Carmen García y Manuel Suárez Cortina la gentileza que tuvieron al invertir una parte de su valioso tiempo en revisar críticamente el texto original.

2 A propósito de esa diversidad, y sobre todo por lo novedoso del enfoque, resulta muy sugerente la lectura del trabajo de Mıguel GonZÁLEZ, R.: «Las culturas políticas del republicanismo histórico español», en Ayer, 53 (2004), pp. 207-236.

3 Sobre el primero véase PÉRez Roldán, C.: El Partido Republicano Federal 1868-1874, Madrid, Endimión, 2001; a propósito del segundo, además de la clásica obra de A. EIRAS RoEL El Partido Demócrata español (1849-1868), Madrid, Rialp, 1961, puede verse el estudio de D. CASTRO ALFín «Unidos en la adversidad, unidos en la discordia: el Partido Demócrata, 1849-1868», en N. Townson (ed.), El republicanismo en España (1830-1977), Madrid, Alianza, 1994, pp. 59-85.

${ }^{4}$ La aparición de alguna otra formación de matiz republicano en las postrimerías del Sexenio no contradice estas afirmaciones, teniendo en cuenta su carácter residual; por ejemplo, Dardé documenta a finales de 1873 un fugaz Partido Republicano Unitario y al mismo tiempo afirma que «era inexistente», paradójico dictamen que se explica por su limitada entidad, ya que la «presunta» agrupación se reducía a Eugenio García Ruiz y «media docena de amigos» (DARDÉ, C.: «Los republicanos», en J. ANDRÉs GALLEGo (coord.), Historia General de España y América. Revolución y Restauración (1868-1931), Tomo XVI-2, Madrid, Rialp, 1981, p. 142).

5 Sobre ella puede verse SUÁREZ CORTINA, M.: «La Unión Republicana: el republicanismo español a comienzos del sigo XX», en Historia 16, 143 (1988), pp. 23-34; también, del mismo autor, "La quiebra del republicanismo histórico, 1898-1931», en N. Townson (ed.), op. cit., 1994, pp. 144 y ss.

6 Sus claves en LóPEZ Estudillo, A.: «El republicanismo en la década de 1890», en J. A. PIQUERAS y M. CHust (comps.), Republicanos y repúblicas en España, Madrid, Siglo XXI, 1996, pp. 216 y ss; duró apenas un año y Pi acabó calificándola como «mera coalición electoral». 
nada «Unión Democrática», binomio en el que el segundo término suplanta y equivale al calificativo «Republicana», como se explicará oportunamente.

En efecto, los autores coetáneos que escribieron sobre la historia del republicanismo español silenciaron su existencia, de tal manera que Enrique Vera y González, Enrique Rodríguez Solís o, más tarde, Álvaro de Albornoz ni la mencionan? ${ }^{7}$. Esto justifica en gran medida que en la historiografía actual suceda algo similar, ya que a ello se añade el condicionante que supone el hecho de que no se conserven importantes fuentes hemerográficas contemporáneas a los momentos más cruciales en la formación de este pensamiento o actitud, sobre todo aquellos en los que se pergeñan sus orígenes, que únicamente logramos esbozar mediante el detenido análisis de polémicas posteriores y el rastreo en ellas de parcas alusiones de carácter retrospectivo que dosifican informaciones exiguas pero, al fin y al cabo, muy valiosas para bosquejar una reconstrucción de aquellos primeros momentos $^{8}$. En ese sentido, mientras que los principales trabajos que estudian el republicanismo español en los primeros años de la Restauración no aluden al movimiento de Unión Democrática, otras monografías que contienen referencias puntuales no lo contemplan en toda su magnitud, como fenómeno de ámbito estatal y manifestación a la vez que palanca de la reorganización que el republicanismo experimentaba a nivel nacional ${ }^{9}$; o sencillamente se le atribuyen unos orígenes, promotores y/o naturaleza que no parecen ajustarse a la realidad ${ }^{10}$.

7 Vera y GonzÁlez, E.: Pi y Margall y la política contemporánea, Tomo II, Barcelona, Tipografía La Academia, 1886; Rodríguez-Solís, E.: Historia del Partido Republicano Español. De sus protagonistas, de sus tribunos, de sus héroes y de sus mártires, Tomo II, Madrid, Imp. Fernando Cao y Domingo de Val, 1893; Albornoz, A. de: El partido republicano. Las doctrinas republicanas en España y sus hombres. La Revolución del 68 y la República del 73. Los republicanos después de la Restauración la crisis del republicanismo. Madrid, Biblioteca Nueva, s. f. Curiosamente, Vera y González refiere la aparición de los que fueron sus primeros valedores en el estadio de la prensa, El Solfeo y La Unión, auspiciados por su correligionario federal Sánchez Pérez (VERA y GonZÁLEZ, E.: op. cit., pp. 968-970), pero evita emplear la expresión «Unión democrática» a lo largo de todo el texto, por más que ésta se le escape al deslizarse en una carta de Pi y Margall que reproduce íntegramente y en la que éste sí la utiliza (Ibidem, p. 980; la carta representaba, además, un hito en el asunto que abordamos, como se verá más adelante); omisión similar puede apreciarse en PI y MARgall, F. y PI y ARSuAgA, F.: Historia de España en el siglo XIX, Tomo VI, Barcelona, Miguel Seguí Editor, 1902, p. 103 y ss.

${ }_{8}$ Todos los títulos de prensa citados en este trabajo se editaron en Madrid, y han sido consultados en la Biblioteca Nacional y la Hemeroteca Municipal de dicha ciudad.

9 Las investigaciones locales o provinciales sobre historia de la prensa, siempre y cuando hayan tenido acceso a periódicos democráticos de esos primeros años y los hayan examinado con cierto detalle, deberían reparar en el posicionamiento de los títulos provincianos respecto al modo de unirse los demócratas, es decir, a la manera de construir esa Unión Democrática, aunque no necesariamente tienen por qué apreciar el fenómeno como parte de un movimiento que se reprodujo en toda España, algo que siempre dependerá de la información que proporcione la prensa estudiada (véase, a título de ejemplo, YANES MESA, J. A.: Prensa lagunera, 1758-2000. Raíz y referencia de los medios de comunicación social en Canarias, San Cristóbal de la Laguna, Concejalía de Cultura y Patrimonio Histórico Artístico, 2002, pp. 46-47).

10 Tal es el caso de M. Artola, que en una escueta alusión define acertadamente la Unión democrática como «la primera versión de las futuras uniones republicanas», pero sitúa su origen en la idea lanzada a finales de 1881 por Carvajal, García y Figueras (véase ARTOLA, M.: Partidos y programas políticos, 1808-1936. Tomo I, Madrid, Aguilar, 1974, p. 381); sin embargo, por aquel entonces el fusionismo ya había devuelto a los republicanos a la legalidad y, realmente, el proyecto había nacido seis años antes en una coyuntura bien distinta, de manera que en 1881 ya había aflorado la división entre sus simpatizantes por el desacuerdo sobre cómo forjar esa Unión, representando el testimonio recogido por Artola sólo 


\section{REPUBLICANISMO Y DEMOCRACIA}

Los demócratas monárquicos que en 1868 no se integraron en el Partido Republicano Federal afirmaban que república y democracia no eran sinónimos, alegando que monarquías como la inglesa y la saboyana respetaban los principios democráticos ${ }^{11}$; pero lo cierto es que en las décadas anteriores al Sexenio republicanismo y democracia "se usaban como sinónimos", tal y como ha estudiado D. Castro, que considera que «no hay motivo suficiente para ignorar la sustancial identidad de fondo" existente entre ambos términos, y que «los testimonios al respecto son múltiples y de todas las procedencias ${ }^{12}$. En esa idea abundaba no hace mucho $\mathrm{O}$. Ruiz Manjón, al destacar que republicanismo y democracia eran conceptos que «habían ido de la mano durante los años de lucha por la implantación de los sistemas liberales, a veces como términos estrechamente relacionados y a veces como sinónimos, ya que ambos subrayaban la soberanía radical del individuo y el respeto a sus derechos políticos» ${ }^{13}$. Por su parte, A. Barrio ha recordado cómo la cultura radical y democrática que durante el Sexenio se divulgó a través de los periódicos y en cafés, clubes, casinos o ateneos estuvo dominada por el símbolo de la República, convirtiéndose ésta en el referente esencial de progreso y libertad y, sobre todo durante la Restauración, en la encarnación del rechazo al doctrinarismo del régimen monárquico ${ }^{14}$, doctrinarismo cuya negativa constituía, según ha apuntado M. Suárez Cortina, «un principio irrenunciable del proyecto republicano ${ }^{15}$. Por no hablar, en palabras de M. Morales, del «relevante papel» que el republicanismo tuvo «en la democratización de las estructuras políticas del país al vehicular las aspiraciones de las clases populares y conformar su identidad colectiva ${ }^{16}$, de manera que «el ideal emancipador de un pueblo» sometido «por

una de las posturas, la partidaria de los comités mixtos. Por su parte, Pere Gabriel ha ofrecido más recientemente una cronología más atinada, ya que sitúa el nacimiento de la propuesta de Unión Democrática en 1876, aunque atribuye su formulación originaria a E. Figueras; véase GABRIEL, P.: «Los días de la República. El 11 de febrero», en Ayer, 51 (2003), pp. 46, 47 y 55.

11 Esteban Navarro, M. A.: «De la esperanza a la frustración, 1868-1873», en N. Townson (ed.), op. cit., 1994, p. 94. El autor recuerda que, aunque «no hicieron de tal creencia un dogma de fe», incluso esos cimbrios, que sencillamente habrían optado por el pragmatismo y antepuesto la prioridad de las libertades a las formas de gobierno, «consideraban la república como la forma de gobierno más acorde con la afirmación del principio de soberanía nacional», de modo que, cuando «la salvación del régimen demoliberal», en febrero de 1873, «dependió únicamente de la proclamación de la República, no dudaron en adherirse a ella con entusiasmo» (pp. 94-95). Los que antepusieron la coherencia al oportunismo siguieron sosteniendo firmemente que la «libertad e igualdad plenas» — la democracia, si se quiere"eran inconciliables con una cabeza del Estado de sucesión dinástica y sin responsabilidades políticas»; véase CASTRO AlFín, D: “Orígenes y primeras etapas del republicanismo en España», en N. TowNSON (ed.), op. cit., 1994, p. 51.

12 Ibidem, p. 51.

13 RuIz MANJón, O.: «La cultura política del republicanismo español», en G. Gómez-Ferrer (coord.), La época de la Restauración (1875-1902). Vol II. Civilización y cultura, Tomo XXXVI Historia de España Menéndez Pidal, Madrid, Espasa Calpe, 2002, p. 185.

14 BARRIO, A.: «Culturas obreras. 1880-1920», en J. Uría (ed.), La cultura popular en la España contemporánea. Doce estudios, Madrid, Biblioteca Nueva, 2003, p. 113.

15 SuÁRez CoRtina, M.: El gorro frigio, Madrid, Biblioteca Nueva, 2000, p. 21.

16 Morales Muñoz, M.: «El republicanismo ochocentista: escuela de ciudadanía», en Ayer, 45 (2002), p. 307. 
los poderes tradicionales» tuvo como basamento «la afirmación del liberalismo en su versión radical- de la democracia y de la República» ${ }^{17}$.

En fin, las conexiones entre democracia y republicanismo han llevado a S. Pérez Garzón a sentenciar que éste, como «alternativa democrática» en el seno del pensamiento liberal, por su «pretensión de justicia social» y su «completo programa de desarrollo educativo, cultural, político y económico", hoy podría identificarse «con un concepto de tan unánime consenso cual es el de Estado democrático y social de derecho ${ }^{18}$. De lo que no cabe duda es del patente empleo de «republicanismo» $\mathrm{y}$ «democracia» como términos intercambiables entre los historiadores, llegando algunos a poner en circulación el vocablo "demorrepublicanos», que "se ajusta bastante a la realidad», al decir de F. A. Martínez Gallego ${ }^{19}$.

Considerando lo que se lleva dicho, no ha de resultar extraño que al comenzar la Restauración, para amplios sectores de la opinión pública, democracia fuera sinónimo de republicanismo y, por extensión, antónimo de monarquismo. Por lo pronto, el cerco legal al que fueron sometidos obligó a los republicanos, para sus apariciones públicas desde la clandestinidad ${ }^{20}$, a embozarse tras eufemismos diversos, entre los que sobresalió, precisamente, el de «demócratas», lo que explica que en aquella delicada coyuntura no se localice ningún «periódico republicano» pero sí «democrático», máscara a la que tuvieron que recurrir por fuerza, además de reprimir en sus páginas, naturalmente, todo contenido antimonárquico, a fin de ajustarse a la nueva legislación — decreto de 29 de enero de 1875-, que estipulaba, entre otras cosas, la prohibición de atacar el sistema monárquico constitucional, ya fueran estas críticas directas o indirectas ${ }^{21}$. A pesar de ese amordazamiento, y con frecuencia debidas a interpretaciones viperinas de la ley y del texto encausado, estuvieron a la orden del día las denuncias de títulos de prensa de ese signo, oscilando sus resultados entre la suspensión más o menos severa y, en los casos más extremos, la supresión directa. Por añadidura, en aquellos momentos se abría una etapa en la que el principio monárquico se reafirmaría en Europa ${ }^{22}$. En

17 SuÁREZ Cortina, M.: op. cit., 2000, p. 20.

18 PÉRez GARzón, J. S.: «El republicanismo, alternativa social y democrática en el Estado liberal», en J. URíA (coord.), Institucionismo y reforma social en España: el Grupo de Oviedo, Madrid, Talasa, 2000, p. 32; también recuerda cómo gran parte de los aspectos sociales y democráticos de la Constitución hoy día vigente fueron tempranamente defendidos por los republicanos del siglo XIX (p. 37).

19 Martínez Gallego, F. A.: «Democracia y República en la España isabelina. El caso de Ayguals de Izco», en M. CHust (ed.), Federalismo y cuestión federal en España, Castelló de la Plana, Publicacions de la Universitat Jaume I, 2004, p. 45.

20 Artola (op. cit., 1974, p. 371) cree más exacto considerar que los republicanos se vieron reducidos «a la inacción» que a la clandestinidad; en todo caso, lo que interesa aquí es consignar que el régimen canovista no reconocía su existencia legal.

21 Seotne, M. ${ }^{\text {a }}$ C.: Historia del periodismo en España 2. El siglo xIX, Madrid, Alianza, 1996, pp. 252253.

22 DARDÉ, C.: «El movimiento republicano. Los hombres, los partidos, los programas y la práctica política», en J. Espadas Burgos (coord.), La época de la Restauración (1875-1902). Vol. I. Estado, Política e Islas de Ultramar. Tomo XXXVI Historia de España Menéndez Pidal, Madrid, Espasa Calpe, 2000, p. 557. 
1883, La República hacía balance de esa situación vivida en la segunda mitad de los 70 , insistiendo en cómo, aun nominalmente atrincherados en la «democracia», su propaganda fue activa y provechosa:

«Ya en la anterior época de Cánovas incurrió éste en el mismo grosero error de aspirar a que se suprimiera a los republicanos, lo cual hubiera sido suprimir una gran parte del país; pero como esto era de todo punto imposible [...] proscribió el nombre.

Los republicanos dejaron de nombrarse republicanos: demócratas se decían [...]; el nombre importaba poco: ellos eran republicanos, y todo el mundo sabía que eran republicanos, y durante los cinco años de dominación canovista se realizó la más activa y más fecunda propaganda republicana. [...] si al subir Cánovas al poder los republicanos eran muchos, cuando abandonó el poder habían multiplicado sus huestes y constituían de hecho, como hemos indicado, la mayoría del país»²3.

Teniendo en cuenta todas las consideraciones hasta aquí expuestas, y de la misma forma que hablar de prensa democrática o de partido democrático ${ }^{24}$ era un eufemismo para referirse a la prensa y el partido republicanos, la «Unión democrática» fue la «Unión republicana» de aquellos años; la única posible en tiempos de asedio y hostigamiento, cuando determinadas palabras eran impronunciables y el vocablo «republicanismo» y sus derivados estaban proscritos, paliando los afectados la prohibición de su empleo mediante el recurso a un término tolerado que fuese, de modo transitorio, equivalente; de manera que la voz «democracia» y su familia léxica desempeñaron esa función. Así se explica que El Manifiesto notificara en 1881 la celebración de un banquete de Unión Democrática, en el café «Inglés» de Madrid, con una gacetilla titulada «El banquete de unión republicana»25; y que, como podrá apreciarse en algunos extractos de las siguientes líneas, no fuese raro que algunos republicanos emplearan en años sucesivos las expresiones «Unión Democrática» y «Unión Republicana» como sinónimas. Naturalmente, la nueva situación no sólo condicionó el propio nombre de la «Unión», sino también sus contenidos; los objetivos confesados por sus partidarios eran por fuerza más limitados que los perseguidos por futuras «Uniones», entre otras cosas porque el propósito inmediato, antes que en instaurar la República, consistía en restaurar las libertades y devolver a los republicanos su condición de «legales», fines supeditados inevitablemente, como es obvio, a una legislación que impedía proyectos más ambiciosos pero, paradójicamente, facilitaba que, al ser las bases del acuerdo más limitadas y elementales, el entendimiento en torno a ellas fuera más amplio

${ }^{23}$ La República, 18-IV-1884.

24 Independientemente de que a ese «partido democrático» se le añadiera la etiqueta de «histórico», "gubernamental» o «progresista», en función de que sus referentes humanos por antonomasia fueran, respectivamente, Pi y Margall, Castelar o, en el último caso, Zorrilla y antiguos Radicales que, como Martos, aún no se habían pasado a la Monarquía.

25 El Manifiesto, 18-X-1881.

26 DARDÉ, C.: «Los partidos republicanos en la primera etapa de la Restauración, 1875-1890», en J. M. Jover Zamora (dir.), El siglo xix en España: Doce Estudios, Barcelona, Planeta, 1974, pp. 444-445. 
y de consecución más asequible que en coyunturas de mayor transigencia. Los impedimentos legales empujaron al republicanismo, siquiera verbalmente, a formar una piña alrededor de un programa común; la falta de acuerdo a la hora de concretar el modo de defenderlo políticamente, de manera conjunta y real, comprometió el halagüeño proyecto, que devino inviable fuera de algunas ciudades en las que se impuso el sentido práctico.

\section{CLAVES, ORÍGENES Y EXTENSIÓN DEL PENSAMIENTO DE UNIÓN DEMOCRÁTICA}

La doble intervención que, manu militari y a cargo de Pavía y Martínez Campos, inauguró y clausuró el año de 1874, abrió una época de incontestable regresión en los derechos, libertades y garantías conseguidos tras la revolución de 1868 , y en cuyos primeros tiempos los demócratas republicanos fueron testigos de un ostensible estrechamiento de sus márgenes de actuación, viéndose arrojados al mundillo del secretismo y la clandestinidad, desde cuya orilla pronto abrigaron la idea de la necesaria inteligencia entre los elementos liberales avanzados, con el objetivo de recuperar las conquistas usurpadas. Cuestionada la soberanía nacional, cercenadas las libertades fundamentales, conculcados los derechos básicos y suprimido - tras las elecciones de 1876-el sufragio universal, cobró especial vigencia ese dicho popular que sentencia que la unión hace la fuerza, y entre los republicanos se fue imponiendo la máxima de que sólo mediante la cohesión se lograría modificar aquel estado de cosas. Indudablemente, la génesis de un pensamiento conciliador pudo haberse desarrollado de modo autónomo en distintos lugares de la geografía nacional, y en cualquier correligionario que antepusiera a la pasión doctrinal y a los personalismos la altura de miras necesaria para comprender que las luchas intestinas hacían flaco favor a la causa republicana. Es por ello que, por lo menos en lo que se refiere a la idea, convendría ser prudentes y, por emplear conceptos extrapolados de la antropología, pensar más en un poligenismo que en un difusionismo lineal y reduccionista. Recuérdese, sólo a título de ejemplo, que ya en 1874-1875 el luego expulsado Ruiz Zorrilla, recientemente convertido al republicanismo y llegado de Lisboa, estuvo en España intentando unificar bajo su mando las distintas agrupaciones republicanas ${ }^{26}$; al margen de que fuera muy difícil que un neófito pudiera encarnar un liderazgo aglutinante, lo que interesa aquí es recordar que en los mismos inicios de la división entre los republicanos ya se incubó en la mente de muchos de ellos el deseo de mitigar la debilidad subsiguiente por medio del entendimiento entre facciones.

La imperiosa y más que recomendable avenencia exigía, como condición sine qua non, que los interesados fueran capaces de consensuar unos puntos mínimos de los que todos ellos participaran, y que sirvieran de programa de encuentro de las diversas familias «democráticas». Sorprendentemente, por las razones apuntadas arriba - la adversidad como acicate-, no encontraron grandes escollos en 
la negociación de ese convenio y acabaron cerrando filas en torno al Título I de la Constitución de 1869 , un referente que no era nuevo ${ }^{27}$ y cuyas limitaciones se justificaban por la apremiante necesidad de alcanzar un acuerdo y la imposibilidad de que sus contenidos se sustrajeran a la nueva legalidad.

El hecho de que las ansias de unión proliferaran en lugares diversos, no es óbice para que su consumación de manera sólida y ejemplar en alguno de ellos pudiera estimular a los correligionarios de otros a agilizar las gestiones para hacer lo propio. Es lo que debió suceder con Oviedo. Todo parece indicar que el nuevo talante aliancista rebasó allí con cierta precocidad el cariz meramente discursivo, lo que explicaría el carácter pionero que diversos testimonios atribuyen a los núcleos democráticos de dicha localidad, capital de la provincia española que en más convocatorias electorales envió diputados republicanos al Congreso en el periodo de 1876-189028. En noviembre de 1887, cuando la idea de la Unión Republicana cobraba nuevos bríos en muchas provincias de España ${ }^{29}$, los partidos republicanos de Oviedo celebraron una reunión conjunta cuyos acuerdos fueron comunicados a Ramón Chíes por Manuel Pedregal —entonces diputado por aquel distrito-mediante una carta redactada en términos esclarecedores, sobre todo en lo que hace a la primera resolución:

«1. ${ }^{\text {a }}$ Renovar el pensamiento de la unión republicana, sin abdicaciones ni sumisiones, propuesto por numerosos republicanos de Oviedo el año de 1876 a los entonces reconocidos jefes de la democracia republicana»30.

Los mismos acuerdos fueron publicados por El País, pero incorporando un matiz que no proporcionaba Pedregal, ya que hablaba del «pensamiento de la unión republicana que los demócratas ovetenses propusieron a sus correligionarios del resto de España en 1876 ${ }^{31}$. En suma, doble destino de la propuesta: líderes nacionales y correligionarios de otras provincias.

Si la idea de forjar una gran Unión Democrática puede documentarse ya en los mismos albores de la Restauración, su praxis definitiva en Oviedo parece haberse demorado algunos meses, hasta ya iniciado el año 1877, a juzgar por los contenidos de una carta remitida en 1879 a El Tribuno por uno de los pioneros de esa

${ }^{27}$ Ese texto seguía siendo el punto de referencia (FERnÁndez Almagro, M.: Historia política de la España contemporánea. 1. 1868-1885, Madrid, Alianza, 1972, p. 331), y ya en 1876 fue enarbolado por Salmerón y Zorrilla en el manifiesto fundacional del precario Partido Republicano Reformista (véase DARDÉ, C.: op. cit., 1974, p. 448).

${ }_{28}$ Véase DARDÉ, C.: op, cit., 1974, p. 447; se incluye un mapa en el que Asturias figura como la única provincia que tuvo representación republicana en cinco ocasiones, seguida por Badajoz, Zaragoza y Canarias, que lo consiguieron en cuatro elecciones (Barcelona, Huesca, Madrid, Alicante y Almería lo hicieron en tres).

29 Precisamente entonces, desde Las Dominicales del Libre Pensamiento (19-XI-1887) se alabó el tradicional sentido práctico de los demócratas ovetenses: «Por allá siempre dando muestras de reflexivos y sesudos».

30 La carta en El País, 12-XI-1887.

31 El País, 14-XI-1887. 
Unión Democrática ovetense, el abogado y masón ${ }^{32}$ César Argüelles Piedra, cuyo testimonio reviste gran valor para ahondar en las estrategias seguidas por el republicanismo durante aquellos difíciles momentos. Según se desprende de su epístola, hacia julio de 1877 «los escándalos de la situación conservadora, el látigo de la tiranía, la desgracia de todos» impulsaron a celebrar una reunión a once personalidades de esa ciudad, «pertenecientes a las distintas facciones de la democracia, desde la radical más moderada hasta la federal más intransigente», postergando transitoriamente la discusión sobre el tipo de república -el vedado término se sobrentiende- preferido por cada cual:

«Ante el peligro común, olvidamos nuestras profundas divisiones personales, dimos tregua a la discusión de nuestras diferencias políticas accidentales, y con palabra de honor quedamos comprometidos a constituir y propagar la Unión democrática sobre las bases de los derechos individuales, y lo que es aspiración común de todos los diversos sentidos de la democracia, respetando el sistema especial de organización que cada cual creyera mejor en su día.

Seis meses después éramos treinta y ocho ciudadanos los que públicamente confirmábamos en todas sus partes aquel acuerdo, decidiendo su propagación por las provincias, y dirigiéndonos especialmente a los que habían sido jefes de las distintas fracciones democráticas ${ }^{33}$.

El doble objetivo de la propaganda — las demás provincias y los jefes de la democracia - se solapa con el reflejado por las declaraciones de Pedregal y de El País indicadas arriba. La génesis ovetense de la Unión Democrática fue confirmada por diferentes títulos de la prensa afines a ese pensamiento, como La Democracia, que subrayó que «fue iniciado y puesto en planta por demócratas de todos los matices y procedencias en Oviedo»34; incluso se apunta en periódicos enfrentados por diferencias «tácticas», como fue el caso de La Unión y El Tribuno. El primero publicó las siguientes declaraciones:

"Oviedo fue la primera provincia que dio el patriótico ejemplo de reorganizar sus fuerzas democráticas, constituyendo un partido disciplinado, fuerte y poderoso, bajo los principios democráticos que son base esencial y legalidad primera para todas las fracciones fieles a las conquistas de la revolución; y de entonces a hoy, no ha habido resentimiento, disidencia, interés, ni oposición capaz de romper la empresa realizada con tanta elevación de miras por aquellos dignos correligionarios. Posteriormente, otras provincias han secundado la obra salvadora iniciada en Oviedo [...]”35.

32 Su pertenencia a la masonería en GUERRA, V.: La masonería ovetense en el siglo xix, una sociabilidad en acción, Oviedo, Facultad de Geografía e Historia de la Universidad de Oviedo, 2003, pp. 33-34.

${ }^{33}$ La carta, con el título «La Unión Democrática», en El Tribuno, 29-VII-1879.

34 La Democracia, 30-VII-1879. El diario progresista-democrático respondía a las burlas de El Tiempo, que ridiculizaba la Unión Democrática: «La obra de los once demócratas de Oviedo puede darse por terminada. ¡Lástima que la modestia de esos once liberales de buena fe no permita que la historia reserve un rincón para consignar sus esfuerzos en pro de esa obra, que ha quedado reducida a los dulces y pasajeros límites de una obra de confitería!». La mofa del diario conservador nos sirve igualmente para refrendar la precocidad de los ovetenses a la hora de poner en práctica el proyecto.

35 La Unión, 21-XII-1878. 
Mientras que el segundo, que llegó a decir de dicha ciudad que era «una de las capitales de más alto sentido político de España, y donde más profundas raíces t[enía] la Unión democrática» ${ }^{36}$, recordaba en cierta ocasión:

«Dos años hace que algunos de nuestros amigos iniciaron tan simpático pensamiento en una carta ya célebre, dirigida a los más caracterizados jefes de la democracia, y desde entonces el movimiento de unión ha seguido propagándose y adquiriendo prosélitos y representantes en todas las provincias [...], con lo cual los demócratas ovetenses ocuparon el primer lugar entre los que siguen las inspiraciones del sentido práctico [...]. Y por esta senda [...] organizáronse nuestros amigos, despertóse el interés de los demócratas todos, salieron de su apatía los más distinguidos e influyentes, y tomó calor y fuerza el movimiento de concentración, de unidad y concordia que activamente sostienen e impulsan los periódicos de nuestra comunión política $[\ldots]^{37}$.

Según la epístola de Argüelles Piedra, hacia finales de 1877 el núcleo de demócratas ovetenses promotor de la Unión Democrática, tras incrementar su número de once a treinta y ocho individuos, habría decidido «su propagación por las provincias» y su comunicación a los «jefes de las distintas fracciones democráticas», algo que según los testimonios de Pedregal y El País ya habrían hecho en 1876, aunque quizá la diferencia estribe en que un año después predicaron esa estrategia con el ejemplo. La figura de Clarín debió resultar crucial en dicha tarea. El célebre autor de La Regenta se habría contado, seguramente, entre los once pioneros ${ }^{38}$, y por aquel entonces era el corresponsal en Oviedo del madrileño El Solfeo, periódico fundado en $1875^{39}$ bajo la dirección del federal Antonio Sánchez Pérez y en el que Leopoldo Alas empleó por vez primera el seudónimo Clarín ${ }^{40}$; tuvo periodicidad diaria a partir del otoño de aquel año, momento en que en su cabecera la ilustración originaria, consistente en una partitura, fue remplazada por otra que cuesta no interpretar como una personalísima representación alegórica de la República ${ }^{41}$.

De esta guisa, y al margen de eventuales contactos de tipo epistolar con grupos democráticos de otras provincias que habrían contribuido a extender el proyecto, los ovetenses encontraron un aliado infinitamente más efectivo en El Solfeo, cuya redacción, por intermedio de Clarín, no sólo habría acogido con ardiente entusiasmo el pensamiento de la Unión Democrática, sino que, como periódico de difusión nacional, se volcó activamente en su propaganda y divulgación por todo el

36 El Tribuno, 15-V-1879.

37 El Tribuno, 17-V-1879.

38 Leopoldo Alas acostumbraba a pasar en Oviedo el verano, estación en la que parece que tuvo lugar la crucial reunión, y además aparecía como miembro de posteriores comités locales de Unión Democrática, igual que el único de aquellos once pioneros cuyo nombre conocemos con certeza, el republicano Argüelles Piedra, ya que en su carta relataba los hechos en primera persona (véase El Tribuno, 11-V-1879).

39 El 25 de febrero se publicó el prospecto y el primer número vio la luz el 7 de marzo.

40 Rodríguez Muñoz, J. (dir.): Diccionario Histórico de Asturias, Oviedo, Editorial Prensa Asturiana, 2002, p. 239.

41 Con un león tendido a sus pies, se ve a una mujer ataviada con una túnica y sentada frente a un atril sobre el que parece alumbrar una lámpara de aceite. 
territorio del Estado. De hecho, en enero de 1878 El Solfeo publicó un trabajo titulado «Entre buenos amigos» y compuesto de tres artículos en los que, reconociendo la existencia dentro de la democracia de diferentes fracciones y negando que ninguna tuviera que plegarse a otra, se sometían a la aprobación de los demócratas españoles algunas consideraciones acerca de la Unión Democrática ${ }^{42}$. Desde mayo, el diario de Sánchez Pérez exhibió el nuevo y comprometido subtítulo de Diario democrático de la mañana ${ }^{43}$, y el mes de julio se despidió de sus lectores propugnando la acción común:

«Unión hoy, entre todas las fracciones del partido democrático, para realizar lo que es común a todas ellas y lo que a todas es necesario para ulteriores desenvolvimientos: Unión mañana, para conservar eso que es común y necesario a todas; sin perjuicio de que legal y paulatinamente procure cada una el logro de sus respectivos ideales ${ }^{44}$.

Entretanto, durante el primer semestre de 1878 y sobre todo en las últimas semanas de vida de El Solfeo, sus impulsores se habrían preocupado de recabar el apoyo de conspicuos demócratas para disolver ex profeso aquella empresa y poner en marcha un flamante y acreditado proyecto que continuara su legado con renovado empeño. Un hito decisivo en tales gestiones fue un banquete celebrado en el restaurante «Fornos» entre caracterizadas personalidades de la democracia ${ }^{45}$, ágape que pudo haber jugado un concluyente rol en la elaboración de las bases que se aprobaron junto con el programa del que iba a ser el primer número del discípulo aventajado de El Solfeo, otro diario democrático que, dirigido por el mismo Sánchez Pérez y con el título elocuentísimo de La Unión, se empezó a vocear por las calles el 27 de julio de 1878. Esas bases subrayaban la continuidad:

«El Solfeo o el periódico que venga a sustituirle, continuará la misma conducta y sostendrá la misma política que en el día sostiene, mientras acontecimientos que pudieran cambiar las condiciones de la prensa no aconsejen otra actitud, que se determinará entonces por los medios y formas que en los estatutos se establezcan» ${ }^{46}$.

Por su parte, el programa del nuevo diario ${ }^{47}$, poco antes de llamar a la unidad y subrayar lo perjudicial del fraccionamiento, arrancaba con una franca exposición de su razón de ser:

42 Según se afirma en La Unión, 15-V-1879.

43 Desde el 1 de mayo de 1878 ( $\left.n .^{\circ} 822\right)$, según el fichero manual de la Hemeroteca Municipal de Madrid.

${ }^{44}$ Citado en La Unión, 15-V-1879 (la alusión a mayo debe tratarse de un error, ya que el último número de El Solfeo, el 893, vio la luz el 25 de julio de 1878, según consta en el fichero de la Hemeroteca Municipal de Madrid).

45 Referido en El Tribuno, 20-VII-1879.

${ }^{46}$ Realmente las bases nunca se hicieron públicas, y el que por una polémica posterior se trajeran fragmentos a colación nos permite conocerlas parcialmente (véase La Unión, 15-V-1879); como en el extracto anterior, no respetamos la cursiva porque no debió figurar en el original, ya que se destaca lo que interesa en la discusión presente.

47 Puede verse en La Unión, 27-VII-1878. 
«Toma hoy cuerpo y reviste su verdadera forma el pensamiento que ha venido inspirando El Solfeo durante su última campaña, y para cuya realización, paciente y laboriosamente, ha tratado de allegar poderosos elementos que constituyen la base de La Unión, diario democrático.

El nombre del nuevo periódico dice bien claro el propósito que le anima, propósito que responde al deseo formulado de una manera explícita en declaraciones públicas, reuniones amistosas y cartas particulares, por la inmensa mayoría de los hombres políticos que, ora bajo la bandera del antiguo partido democrático, ora bajo la enseña del numeroso partido radical, han representado los distintos matices de la Democracia Española

[...] Nuestro deseo se extiende a congregar bajo principios comunes a cuantos entienden (sean cuales fueren su procedencia y su objetivo) que no hay otro medio de encauzar nuestra desordenada existencia política [...] que la proclamación de aquellas LIBERTADES NECESARIAS y aquel respeto absoluto a la VOLUNTAD DE LA NACIÓN, expresada en Cortes elegidas por SUFRAGIO UNIVERSAL [...]».

Después explicitaba los mínimos comunes sobre los que articular la unidad y al final persuadía a los reticentes de que su aceptación no implicaba la abdicación de las ideas de cada cual:

«En [la Constitución de 1869] es visible, es palpable la diferencia que va del título I a los restantes [...]. En ese título se establecen formuladas de un modo satisfactorio, en términos precisos, fuera de todo sentido de escuela y toda vaguedad doctrinaria, aquellas libertades necesarias [...] a que hoy todo el mundo culto presta acatamiento: la seguridad personal, la inviolabilidad del domicilio y de la correspondencia, la libertad de imprenta, la de reunión pacífica y de asociación moral, el derecho de petición y representación a los poderes públicos, su responsabilidad, la libertad de cultos, la de tránsito y locomoción, y, en fin, el sufragio universal y el régimen representativo. Pues bien: he aquí una bandera para todos los devotos del espíritu moderno; esta es la que lanzamos al viento pidiendo la cooperación activa de todos los liberales y demócratas de España, hoy debilitados y casi inermes por su separación y su antagonismo.

Sin duda alguna por bajo de aquellos principios quedarán muchas diferencias de escuela o de partido: no pretendemos que nadie deponga su particular punto de vista. Contamos con ello [...]».

Algunos de los «poderosos elementos» allegados por La Unión fueron publicitados por el diario en una circular enviada «a sus amigos», que contenía una «lista de los accionistas» que secundaron el proyecto de unir a los elementos democráticos que aceptaban un credo común ${ }^{48}$. En ella figuraban, por ejemplo, Nicolás Salmerón, Francisco Pi y Margall, Eduardo Chao, Gumersindo de Azcárate, Leopoldo Alas o Manuel Pedregal, entre otros, además de representantes del antiguo Partido Radical como Manuel Ruiz Zorrilla, Eugenio Montero Ríos, Laureano Figuerola, Gabriel Rodríguez o Rafael María de Labra, que también asumió la de-

${ }^{48}$ Sabemos de su existencia por una alusión de La Gaceta Valenciana citada en La Unión, 31-VII1878. 
fensa del nuevo periódico en varias de las muchas denuncias de que fue objeto, lo mismo que Estanislao Figueras y el citado Azcárate ${ }^{49}$. Curiosamente, cuando algunos de los diputados que durante varios años fueron conocidos como «republicanos sueltos", y que en su día habían respaldado la Unión Democrática, acordaron en 1887 reconstituirse con la denominación de «minoría de Unión republicana", lo hicieron publicando un manifiesto-programa que proclamaba de nuevo los «derechos contenidos en el título I de la Constitución de 1869»50; entre ellos se contaban Pedregal, Labra, Azcárate y Villalba Hervás, quienes en cierta ocasión fueron referidos por El País como «los antiguos apóstoles de la Unión democrática ${ }^{51}$.

Conviene no perder de vista los vínculos con Asturias de algunos de los citados, como es el caso de Pedregal, nacido en Grado, o el de Azcárate, de madre gijonesa; pero sobre todo recuérdese que Labra, que también fue «colaborador» de $\mathrm{La}$ Unión ${ }^{52}$, aunque residía en Madrid veraneaba cada año en su casa de Abuli, en las cercanías de Oviedo $^{53}$, por lo que es más que posible que se encontrara allí en julio de 1877 y que Clarín no fuera la única correa de transmisión a la redacción del periódico del proyecto ovetense de Unión Democrática, cuyos canales de difusión debieron ser, pese a todo, harto complejos. También es obligado consignar la defección de Castelar, que dirigió desde El Globo una campaña contra la Unión Democrática que empujó a muchos de los seguidores del malagueño que eran partidarios de esa acción común a protagonizar disidencias en los comités posibilistas de algunas ciudades (Bilbao, Zaragoza, Huesca, Jaén, Málaga...) $)^{54}$. Bastante ilustrativo es que, al reproducir una carta del republicano francés Gambetta, el órgano de Castelar en la prensa, El Globo, llegara al extremo de suprimir dos palabras — «unión» y «concordia»— que convenían a la política seguida por los partidarios de la acción común ${ }^{55}$. De ahí el enojo de La República cuando Castelar reaparece en Lugo en 1885 predicando pasajeramente «lo que rechazó antes», la Unión Democrática, "tan a deshora», "cuando nadie piensa en ella» y con la sospechosa connivencia de algún periódico «tan conservador y tan ministerial» como La Patria ${ }^{56}$.

49 La Unión, 18-VIII y 14-XI-1878; 19-I-1879.

50 El manifiesto en La República, 2-XII-1887.

51 El País, 3-XI-1887.

52 Así es referido, por ejemplo, en La Unión, 1-XI-1878.

53 Rodríguez Muñoz, J. (dir): op. cit., 2002, p. 603.

54 La Unión, 6 y 15-VIII-1878; 4, 5, 9, 10 y 30-III-1879.

55 La Unión, 17-VIII-1878. Este fenómeno podría explicar las omisiones de Vera y González señaladas al principio y, seguramente, tan «interesadas» como las de los castelarinos, ya que la obra se escribe en un momento en que el Partido Federal, en el que militaba su autor, repudiaba la Unión Democrática y prefería la coalición, dos fórmulas que los pimargallianos distinguían escrupulosamente (el comité mixto frente al comité homogéneo o de partido, como se explicará más adelante).

56 La República, 14-VIII; 16 y 18-X-1885. Ya en 1880 pueden detectarse afirmaciones de Castelar ambivalentes: «La bandera de la unión de la democracia es mi bandera (...). Urge, pues, esa unión. Pero si la democracia la intenta con la utopía socialista o federal, está perdida; (...)» (véase PI Y MARGALL, F. y PI y ARsuagA, F.: op. cit., p. 173); en la práctica, el moderantismo de la vía castelarina recelaba de una parte nada despreciable del republicanismo del momento y declaraciones de este tipo tenían mucho de demagogia, ya que las censuras de El Globo al proyecto de Unión Democrática eran inequívocas. 
Por lo demás, el grueso del republicanismo español pareció cerrar filas en torno a la idea de constituir una Unión Democrática y a su sombra, con esa bandera, tuvo lugar su reorganización, su reaparición pública y la reactivación de su tejido organizativo. Lugo, Logroño y Barcelona fueron algunos de los primeros lugares que respaldaron con los hechos ese proyecto de mancomunidad ${ }^{57}$; también en Navarra y en Tenerife, lugar este último en el que parece haberse dado cierta simultaneidad que refuerza la idea ya apuntada de que el pensamiento unionista era antiguo y, en gran medida, ubicuo, y que cosa distinta fue su proyección práctica ${ }^{58}$. Ciertamente, La Unión redobló los desvelos de El Solfeo y se afanó en cumplir los objetivos que se había propuesto, convirtiéndose pronto en una palestra hacia la que convergieron los núcleos republicanos de la práctica totalidad de las provincias, que masivamente remitieron cartas de adhesión en las que notificaban la constitución de comités de Unión Democrática; esta práctica convierte el diario, a día de hoy, en una fuente excepcional para el estudio del republicanismo provinciano en aquellos primeros años. Entretanto, muchos periódicos se fueron posicionando a favor de esa Unión Democrática y nacieron otros con ese proyecto bajo el brazo ( La Voz Montañesa, La Publicidad, La Nueva Prensa, El Pueblo, La Igualdad...); unos y otros constituyeron una palanca para la reorganización a la vez que una expresión tangible de la misma, y todos combatieron los esfuerzos de la prensa ministerial y ultramontana (El Mundo Político, El Conservador, La Época, El Tiempo, La Fe...) por dinamitar sus empeños conciliadores. No era la primera vez que la prensa se convertía en una plataforma por las libertades ${ }^{59}$, y desde luego no sería la última, como demostró la Asamblea de la Prensa que, patrocinada por La República en 1889, precedió a la reunión de la Asamblea Nacional Republicana al año siguiente ${ }^{\infty}$. Por ello, en la dimensión que señala Suárez Cortina de la prensa republicana "como instrumento de socialización de la cultura republicana»" ${ }^{61}$, puede incluirse, junto a la difusión de valores, cosmovisiones y propuestas políticas, una faceta estratégicamente aglutinante en determinadas coyunturas.

\section{LA ENDÉMICA DISCORDIA TRICOLOR}

La primavera de 1879 fue testigo de la publicación, casi el mismo día, de sendos documentos que hicieron de la Unión Democrática, en tanto que proyecto

57 Según se indica en La Unión, 2-I-1879.

58 En una carta enviada en 1887 por Villalba Hervás al director de El Memorandum, de Santa Cruz de Tenerife, le recordaba cómo «la idea de unión, concentración, liga —el nombre poco importa - entre todos los republicanos» la habían formulado ellos junto a Suárez Guerra «a raíz misma de la restauración, a la vez que surgía en Oviedo, Navarra y no recuerdo si en alguna otra provincia» (véase El País 3-XII1887).

59 En otoño de 1842, por ejemplo, el progresista El Eco del Comercio invitó al resto de los directores de periódicos a coligarse en defensa de las libertades; Díez TorRE, A. R.: «Las regencias de María Cristina y de Espartero", en J. PAREDES (coord.), Historia contemporánea de España, 1, Siglo XIX, Barcelona, Ariel, 1998, p. 246).

60 LÓPEZ Estudillo, A.: op. cit., 1996, p. 210 y ss.

61 Suárez Cortina, M.: op. cit., 2000, pp. 81-82. 
de ámbito estatal, un mero conato. En aquel momento el consenso respecto a la urgencia de la unidad y los puntos programáticos sobre los cuales conformarla encontró un poderoso obstáculo al perfilarse dos fórmulas para hacerla efectiva que, pese a su inocente apariencia, resultaron irreconciliables y estuvieron en la base de una polémica enconada - sobre todo en la prensa- y especialmente nociva para la coordinación de fuerzas: por un lado, la formación de comités homogéneos de cada partido, que propiciarían una coalición de esos partidos para los fines que les eran comunes, tras haber delegado en sus líderes esa responsabilidad; por otro lado, la creación de comités mixtos que, integrados por demócratas a título individual -al modo de las ligas inglesas - y sin considerar su militancia en un partido, lucharían por esos mínimos objetivos compartidos.

Por la primera opción se inclinó Pi y Margall, que mostró gran celo por preservar la identidad del Partido Federal y evitar toda mezcolanza, interpretando la pertenencia a comités mixtos como la abdicación de principios de su ideario que consideraba vertebrales (pacto, autonomía...). Fue secundado por el grueso de los federales pactistas y por la prensa afín, empezando por La Unión, que fue patentizando gradualmente el ideario de Sánchez Pérez y su adhesión a las tesis del líder del partido, lo que le valió la pérdida del respaldo de muchos colaboradores y apoyos contrarios a esa táctica ${ }^{\infty}$, que se integraron en otros proyectos acordes con la suya propia; a su redacción llegaron las adhesiones de los comités que se fueron constituyendo en provincias según esos parámetros. También se opuso a los comités mixtos Ramón Chíes ${ }^{63}$. El caso es que el célebre autor de Las Nacionalidades, que no se encontraba tan apartado «de la política republicana» como han sugerido algunos de sus biógrafos ${ }^{64}$, envió una carta —uno del par de documentos citado-a la reunión que los federales barceloneses celebraron en el teatro Tívoli el 20 de abril de 1879; en ella excusaba su ausencia e insistía en la conveniencia de «fijar el alcance y el sentido» de la Unión Democrática, haciéndolo del modo que sigue:

«[...] sería indudablemente una quimera intentar refundir [los partidos], máxime cuando unos y otros profesan de buena fe sus ideas, y no es de partidos serios irlas cambiando [...] al compás de pasajeras circunstancias.

[...] Deslindados los campos, la unión democrática será lo que debe ser: la perfecta alianza de los partidos para realizar los fines que les son comunes; la independencia de cada uno de los aliados para todos los fines que les sean peculiares y propios. Así he entendido siempre la unión, así la sigo entendiendo. Nada por lo tanto de comités mixtos. Cada partido debe tener su organización, y los hombres que estén al frente de cada organización entenderse [...]»65.

62 De esa fuga se habla en El Mundo Moderno, 1-III-1881.

63 Véase «La Unión Democrática», en El Voto Nacional, 10-VII-1881 (Chíes dirigía este diario).

64 Así Farré Parareda en Francisco Pi y Margall. El apóstol del republicanismo federal español, Barcelona, Edit. Asther, 1931, p. 49. Por añadidura, Pi había redactado el 28 de marzo un célebre e influyente manifiesto por el retraimiento titulado «A los electores demócratas» y suscrito por unos ciento treinta ex diputados y ex senadores (una copia en La Unión, 29-III-1879).

${ }_{65}$ Una reproducción íntegra de la carta en La Unión, 18-V-1879, y también en la obra citada de Vera y González, ya que es a la que me refería en la nota 7. 
La segunda fórmula tuvo como principal valedor en la prensa a El Tribuno, que aglutinó a muchos de los antiguos apoyos de La Unión, encontrándose entre sus colaboradores, por ejemplo, Azcárate, Figueras, Salmerón, Labra, Pedregal, Muro o Chao ${ }^{66}$. Esta postura se había definido y hecho pública en el segundo de los documentos referidos, la carta-circular que redactó el comité de Unión democrática madrileño el 19 de abril, que además contenía alusiones al pactismo implícitamente reprobatorias que justificarían el recelo de Pi:

«La Unión democrática no puede ser una fusión de partidos, ni un partido nuevo [...]. Y no puede ser coalición, porque estas suponen la existencia de los partidos constituidos y unánimes en sus particulares tendencias; y es notorio, por ejemplo, que muchos federales no están conformes respecto al principio generador, para otros, de la federación (el pacto, derecho de los Cantones) [...] Así la Unión democrática no puede ni debe ser hoy sino una liga de todos los demócratas que reconocen como primera necesidad el afirmar y conquistar lo que es condición esencial de la vida para todos; punto de alianza para las diversas fracciones y parcialidades $[\ldots]$.

Cuando eso se haya conseguido, será ocasión de que se manifiesten las distintas tendencias generales [...]. Por el contrario, afirmamos la imperiosa urgencia de que todos los demócratas se unan bajo una acción común y directa para el fin común, aplazando particularidades ideales hasta haber alcanzado las que son condiciones necesarias de existencia para toda la democracia española» ${ }^{67}$.

\section{BALANCE}

En el plano teórico, el pensamiento de Unión Democrática representó una actitud fresca y concertadora; un talante conciliador -interesado, si se quieredesarrollado frente a la adversidad de las circunstancias, al socaire de una coyuntura especialmente aciaga durante la cual el republicanismo, declarado ilegal hasta 1881, fue sumido en el ostracismo en un momento, para colmo de desgracias, en el que presentaba importantes divisiones internas. La nueva estrategia persiguió una acción mancomunada que dilatara su margen de maniobra y se esforzara en postergar cizañas y concentrar las energías de las distintas familias democráticas para recuperar las libertades, las garantías y los derechos elementales logrados en 1868 y mutilados desde 1874. En 1881, la Unión Democrática de los primeros años se contemplaba retrospectivamente como «un procedimiento de agrupación de las dispersas fuerzas democráticas» que resultó "conveniente cuando era imposible la organización de los partidos con sus propios nombres» 68 . Por sus endémicas controversias internas, con frecuencia derivadas en auténticos diálogos de sordos, los mismos que habían sido partidarios de la Unión Democrática acabaron anteponiendo las rencillas personales y doctrinales a la perentoria

\footnotetext{
66 Una relación de colaboradores en El Tribuno, 18-VII-1879.

67 Puede verse completa en El Tribuno, 19-VII-1879.

68 El Voto Nacional, 9 y 17-VII-1881.
} 
necesidad de coordinar esfuerzos. Huelga señalar que con la formación de la Asociación Republicana Militar, iniciada a finales de $1880^{69}$, los militares republicanos, que por su condición profesional asumían evidentes riesgos añadidos, pronto lograron - quizá con la disciplina inherente al gremio como factor coadyuvante- lo que costó al republicanismo civil titánicos y, no pocas veces, estériles denuedos ${ }^{70}$.

Aun sin llegar a convertirse en sólido proyecto nacional, la Unión Democrática fue rentable en aquellos lugares donde la perspicacia y el sentido práctico de la colectividad de opinión democrática primaron sobre otras consideraciones, al margen de la forma adoptada, que al fin y al cabo, y para bien o para mal, dependió más de las circunstancias locales que de las recomendaciones de los líderes más autorizados; por ejemplo, allí donde un partido no hubiera constituido aún el pertinente comité no podría formalizar la coalición, resultando más conveniente el comité mixto, y de hecho ambas fórmulas convivieron en aquella época. En Oviedo, la candidatura de la Unión Democrática arrasó en las municipales de la primavera de 1879, al obtener las catorce vacantes en juego, de lo que resultó, sumando dos que ya tenían, un Ayuntamiento con dieciséis concejales demócratas frente a doce ministeriales ${ }^{71}$; la ciudad que había visto nacer la praxis aliancista conservó en los años siguientes ese clima de entendimiento, materializándose en la formación de sucesivos comités imbuidos de ese espíritu. A principios de 1881 Ruiz Zorrilla llamaba a imitar el ejemplo dado por la juventud de Madrid, Oviedo, Valencia, Huesca y Cervera, poblaciones de las que era bien conocida la inteligencia alcanzada por sus sectores democráticos ${ }^{72}$.

Con el tiempo, la Unión Democrática se identificó frecuentemente con la fórmula del comité mixto y la coalición con la del homogéneo, sobre todo en el campo federal, lo que explica que Fernando Garrido distinguiera en septiembre de 1881 no ya entre partidarios de comités homogéneos o mixtos, sino entre simpatizantes de la "coalición» o de la «unión democrática» ${ }^{73}$. A lo largo de los ochenta Pi y Margall siguió distinguiendo escrupulosamente entre "coalición», de un lado, y «unión» - al margen del calificativo- o «fusión», de otro, vinculando los dos últimos términos a la «mezcla», la renuncia de doctrinas y la perturbación ideológica del disciplinado partido; de hecho, ese recelo explica que no respaldara la estrategia iniciada con la Asamblea de la Prensa en 1889 y que acabara distanciándose del marqués de Santa Marta.

La idea de la acción común había renacido con fuerza tras la muerte de Alfonso XII, a finales de 1885, y al año siguiente pudo forjarse una coalición en la que

69 DARDÉ, C.: op. cit., 1981, p. 144.

70 Unos apuntes sobre ella en Busquets, J.: «La Asociación Republicana Militar», en Historia 16, 128 (1986), pp. 20-28.

71 La Unión, 17-V y 26-VI-1879.

72 El Manifiesto, 11-I y 1-II-1881.

73 El Manifiesto, 10-IX-1881. 
entró Pi; cuando éste la rompió en 1887 se generaron importantes disidencias en el partido, de manera que, mientras algunos hicieron caso omiso de las órdenes del Consejo y se integraron en comités mixtos o formaron coaliciones locales, otros abandonaron la organización de Pi y aceptaron la jefatura de Jaime Martí-Miquel, con el semanario Las Regiones como portavoz en la prensa. Por aquellos tiempos el diario federal La República, declarándose partidario de la coalición «desde 1875», denunciaba la creación de comités mixtos "en muchas localidades» y, alegando que «la coalición no es la confusión», abogaba por forjarla «sin mixtificaciones", argumentando que no podía «tener otro objeto que la realización de un fin común» y despreciando «la idea disolvente y perturbadora de la absurda unión democrática» ${ }^{74}$; en realidad, las frecuentes llamadas de atención a los federales de tal o cual localidad en ese sentido demostraban que, en la práctica, no fueron pocos los que desoyeron las recomendaciones del partido y se adaptaron a las circunstancias locales; en 1881 El Voto Nacional elogiaba la «personalidad sobrada para discurrir por sí mismos", frente a las jefaturas, de algunos republicanos -en este orden- de Oviedo, Pamplona, Barcelona, Zaragoza, Sanlúcar, Madrid, Cádiz, Albacete, Ciudad Real y Valencia ${ }^{75}$. En realidad, los pimargallianos habían empezado a abominar de la Unión Democrática desde el momento en que ésta tendió a asociarse con los comités mixtos, por lo que ya en 1881 consideraban que sólo había generado «una honda división en [su] campo» ${ }^{76}$.

Cuando los intentos de coordinar la lucha recibían ya otras denominaciones Unión republicana, coalición...-, la vieja expresión de Unión Democrática aún sobrevivía en las cabeceras de algunos periódicos que habían nacido en los tiempos de la clandestinidad canovista y que gozaron de larga vida, como los que con el nombre de La Unión Democrática se publicaron en Albacete (al menos hasta 1892) y en Alicante (¡hasta 1920 ! $)^{77}$.

74 La República, 24-IV y 23-IX-1884; 11, 12 y 19-XII-1885.

75 El Voto Nacional, 25-VI-1881 (no necesariamente parece referirse sólo a los federales orgánicos).

76 El Mundo Moderno, 21-VI-1881.

77 Ambos habían nacido en 1879. Véase Moreno SÁEz, F. (Ed.): La prensa en la ciudad de Alicante durante la Restauración (1875-1898), Alicante, Instituto de Cultura «Juan Gil-Albert», 1995, pp. 407 y ss., y SÁNCHEZ SÁNCHEZ, I.: Historia y evolución de la prensa albacetense (1833-1939), Albacete, Instituto de Estudios Albacetenses, 1985, pp. 126-128. 